\title{
How Many Authors Does It Take to Publish an Article? Trends and Patterns in Political Science*
}

\author{
Bonnie S. Fisher, University of Cincinnati \\ Craig T. Cobane, University of Cincinnati \\ Thomas M. Vander Ven, Hofstra University \\ Francis T. Cullen, University of Cincinnati
}

Politic

olitical scientists have a tradition

of reflecting on the evolution and

state of their discipline. Numerous

studies have examined rankings of

departments (Klingemann 1986;

Jackman and Siverson 1996; Lowery

and Silver 1996; Miller, Tien, and

Peebler 1996b; Morgan and Fitzgerald 1977), graduate programs (Katz and Eagles 1996), journals (Baum et al. 1976; Garand 1990; Giles and Wright 1975; Giles, Mizell, and Patterson 1989; Lester 1990), and citation rates (Cnudde 1986; Gleditsch 1993; Gleditsch 1996; Klingemann, Groffman, and Campagna 1989; Miller, Tien, and Peebler 1996a). The status of women in the profession-ascertained by, for example, counting the number of Ph.D.s granted over time-has also become a subject of study (Burton 1979; Sarkees and McGlen 1992; Kelly, Williams, and Fisher 1993; Hesli and Burrell 1995; Young 1995).

We continue the self-study tradition by examining an area that has not received much attention among political scientists: trends and patterns of multiple-authored journal articles in political science over time (for an exception, see Miller, Tien, and Peebler 1996a, Table 7). In the social sciences more generally, patterns of multiple authorship have increasingly become the focus of scholarly attention and concern (Endersby 1996; Fisher et al. 1998; De Maio and Kushner 1981; Hudson 1996; Wildavsky 1986). About half of all articles published in toptiered professional social science journals are written by two or more scholars; two or three decades ago, the proportion of multiple-authored articles was one-quarter to one-third of all social science articles (Endersby 1996; Hudson 1996; Miller, Tien, and Peebler 1996a).

The explanations offered for this increase in multiple authorships fall into three loosely defined categories (see Endersby 1996, Hudson 1996, Miller, Tien, and Peebler 1996a). First, the pool from which suitable collaborators can be found has steadily expanded over the last fifty years. Between 1950 and 1990, the
Bonnie S. Fisher is an associate professor in the department of political science at the University of Cincinnati. She has written several articles that examine issues concerning the extent and nature of college student criminal victimization. Criminology, Crime and Delinquency, Public Administration Review, and the ANNALS have published her most recent work.

Craig T. Cobane is a Ph.D. candidate in the department of political science at the University of Cincinnati. His research addresses the effectiveness of antiterrorism legislation and its impact on civil liberties in a democratic context. His work has appeared in the Journal of Criminal Justice Education, PS: Political Science and Politics, and The International Journal.
Thomas M. Vander Ven is an assistant professor in the department of sociology and anthropology at Hofstra University. His research interests include the relationship between maternal working conditions and delinquent involvement.

Francis T. Cullen is distinguished research professor in the department of criminal justice at the University of Cincinnati, where he also holds a joint appointment in sociology. He is the author of Rethinking Crime and Deviance Theory, coauthor of Reaffirming Rehabilitation, Corporate Crime under Attack, Criminological Theory, and Criminology, and coeditor of Contemporary Criminological Theory. number of Ph.D.s awarded in the social sciences has grown $283 \% .^{1}$ During the same period, there was a $288 \%$ increase in the number of Ph.D.s awarded in political science (National Research Council 1995, Table A). With this increase in the size and expertise of disciplines, we have witnessed the development of specialized "sections" and journals, which may give authors more opportunities to interact with academics possessing similar research interests, and the creation of multidisciplinary journals, which are outlets for the growth in subject areas covered by social scientists.

Second, the nature and execution of the scholarly task has changed over time. Large-scale data collection efforts, the availability of large data sets from archival depositories such as the Inter-university Consortium for Political and Social Research (ICPSR), and the increasing technical and statistical sophistication of data analyses have led to more scholarly specialization and, in turn, division of labor on research projects. These changes, coupled with the availability of external funding from research agencies such as the National Science Foundation (NSF), have helped to create "invisible colleges" (De Maio and Kushner 1981, 191). These invisible colleges, according to Price and Beaver (1966, 1017), develop from a core of researchers (with several singleauthored and multiple-authored papers) and a floating population consisting of occasional collaborators.

Third, simultaneously, the development of technology has made collaboration more accessible across time and space. Overnight mail, photocopiers, computers, fax machines, email, and teleconferencing make long-distance collaboration 
considerably less daunting and time consuming. In essence, the invisible college of the 1960s and 1970s has been replaced by the "virtual college," or, more appropriately, the "virtual research center," of today.

Some see a potential downside to multiple authorship of scholarly articles. Hudson $(1996,157)$ suggests that collaboration leads to intellectual compromises that make projects less innovative, to reduced productivity for individual authors, and to a reduction in scholarly reputation for collaborators. Other scholars see collaboration as a means for providing more opportunities to mentor graduate students, to rekindle the scholarly interests of the faculty who have become less productive, to build social relationships and scholarly networks within and between departments, and to produce higher quality work as measured by the number of citations (Eisenhauer 1997; Durden and Perri 1995; Endersby 1996; Wildavsky 1986).

Whether multiple authorship is good or bad for the collaborators or the profession, its prevalence merits discussion because of publications' importance in determining the fate of faculty in merit raises and in influencing promotion and tenure decisions at universities and colleges. Anecdotal evidence abounds about merit increases being withheld and tenure and/or promotion being delayed or denied because multipleauthored publications have been discounted. Although few would debate the need for faculty to establish an "independent" scholarly agenda, the risk exists that multiple-authored works are seen as having little value.
If collaborative scholarship has become the norm over time-especially for certain types of research projects-it may be misguided to interpret a vita containing many multiple-authored publications

as showing a lack of scholarly independence.

In this article we explore trends and patterns in multiple authorship in political science over the past four decades. Research on multiple authorship in other disciplines has uncovered a steady increase in published research collaboration. This upward trend has been reported in economics (Durden and Perri 1995; Hudson 1996), sociology (Grant and Ward 1991), and criminal justice (Fisher et al. 1998). Consistent with these trends, we expect to see increasing proportions of multiple-authored works in political science, especially for articles detailing empirical work involving statistically sophisticated techniques.

\section{Methods}

To compare publication trends and patterns for single- and multiple-authored articles over time, we collected data from articles published in three political science journals. We selected the American Political Science Review (APSR), American Journal of Political Science (AJPS), and Journal of Politics $(J O P)$.

These three journals were selected for several reasons. First, they are among the oldest journals in the discipline. APSR was first published in November 1906, JOP began publishing in 1939, and AJPS appeared in May 1957, as the Midwest Journal of Political Science. Second, these journals are consistently ranked among the most important and prestigious journals in the field (Giles,
Mizell, and Patterson 1989; Garand 1990; Lester 1990). Because of their reputation, scholars have frequently used them when examining scholarly productivity and author prestige (Young 1995; Endersby 1996; Miller, Tien, and Peebler 1996a). Furthermore, APSR is the official publication of the American Political Science Association. The two largest regional associations, the Midwest Political Science Association and the Southern Political Science Association, publish $A J P S$ and $J O P$, respectively (Giles, Mizell, and Patterson 1989, 615).

Our sample included the first issue of the 1950 volume through the last issue of the 1996 volume. ${ }^{2}$ We chose 1950 as the initial year for several reasons. First, it marks a time of substantial change and "a period of great intellectual ferment in the discipline" (De Maio and Kushner 1981, 183). Second, the 1950s mark the introduction of rudimentary quantification in the social sciences and the ascendency of the behavorialist movement in political science (Susser 1992, 5). Finally, an end point at or near mid-century is a popular one for researchers (see, for example, De Maio and Kushner 1981; Hudson 1996; Miller, Tien, and Peebler 1996a). Selecting a similar endpoint allows us to compare our findings to the findings of others.

We included in the analysis only unsolicited, refereed articles-fulllength research articles, research notes, and review essays of the literature on some specific substantive field. We excluded from consideration standard book reviews, presidential addresses, editorial comments, replies, rejoinders, controversies, communications, errata, and commentary. We also did not include articles in special issues that published the works of only invited scholars.

We examined each article and collected and coded several pieces of information. ${ }^{3}$ First, we counted the number of authors for each article. Second, we collected demographic information about the sex of the author(s). ${ }^{4}$ We coded the sex of the author(s) as: male/all males, female/all females, and a mixture of 
Figure 1

Percent of Multiple-Authored Articles by Year of Publication

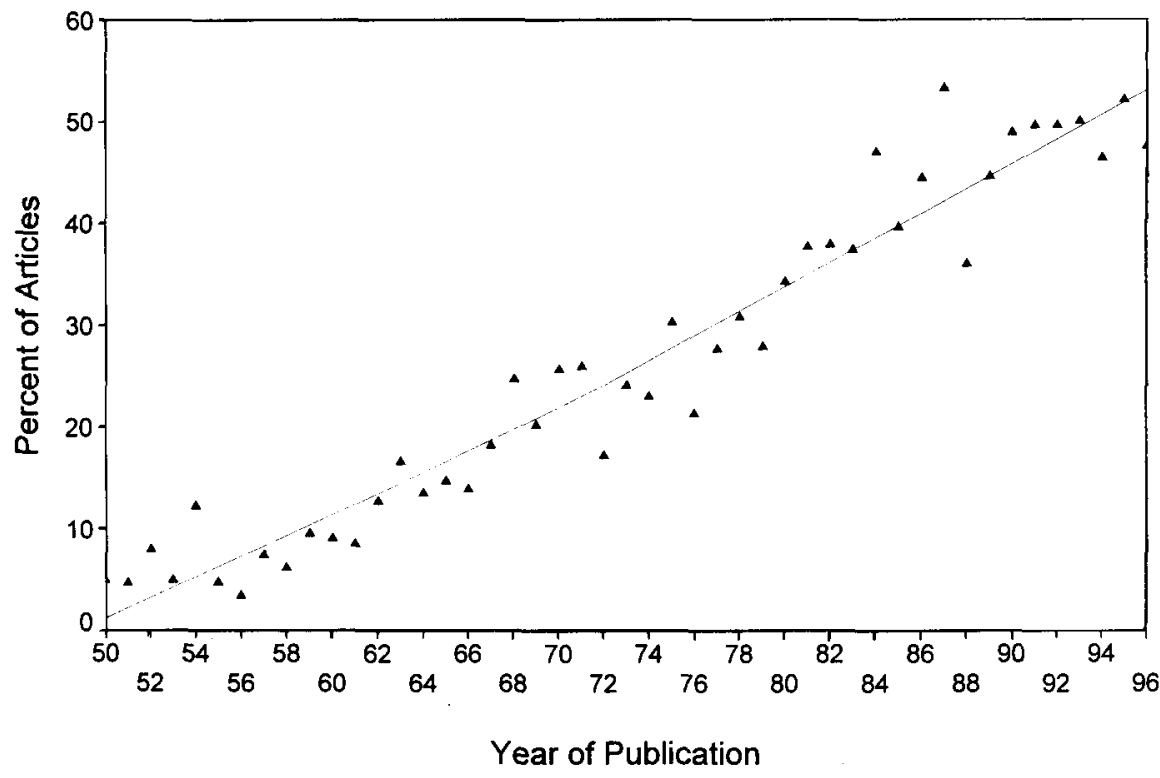

Note: $\alpha=.99$ male(s) and female(s). Third, we collected content information about each article. Specifically, we recorded the type of article, type of data collection employed, ${ }^{5}$ and type of statistical analysis reported. We determined the type of article by assessing the content of the articles and we coded each article as theoretical or empirical using quantitative data, qualitative data, or a mixture of both. Theoretical articles tical or methodological discussions, mathematical theory explications, and computer simulations with no statistics. Empirical articles include case studies, primary and secondary data analyses, mathematical theory explications with statistical applications, and computer simulations with statistical applications. We determined the type of statistic by identifying the highest level of statistics reported and coded it as none, descriptive (e.g., measures of central tendency, percentages), bivariate (e.g., measures of association), or multivariate (e.g., regression-based models, LISREL, time-series).

As the coding progressed, we were confronted with a few unforeseen issues due to changes in the respective journal's format (e.g., the detail of biographical information include theoretical arguments, statis- provided) or issues beyond our control. First, institutional affiliation and author status (as noted earlier) were often unavailable for coding purposes. Second, problems occurred in verifying the sex of the author when journals used only initials for the first name. This was especially troubling in the early years of publica- tion, because we were less familiar with the identities of authors working in the 1950s and 1960s. We also experienced a related problem in verifying the sex of the author with some non-English first names, androgynous names, or ambiguous names. If none of us could confirm the sex of the author, or we could not determine it from other sources, we coded the sex of that author as a missing value. We should note that authors of other citation studies have experienced similar problems with the categorization of initials and names (see Gleditsch 1996). In all, 5,150 articles were included in our analysis.

We analyzed our data using two techniques. First, each figure presented here depicts the relationship between year of publication and the respective variable so that the reader can easily see the annual data aggregated across the three journals and the trends and patterns over the entire time series. We used a local regression scatterplot smoother, loess, to produce the smoothed curves in the figures (see Beck and Jackman 1998; Cleveland 1979, 1984; Jacoby 1997). ${ }^{\circ}$ We selected the value of the smoothing parameter, $\alpha$, for each curve by analyzing the loess residuals plotted

\section{Figure 2}

Percent of Multiple-Authored Articles by Number of Authors

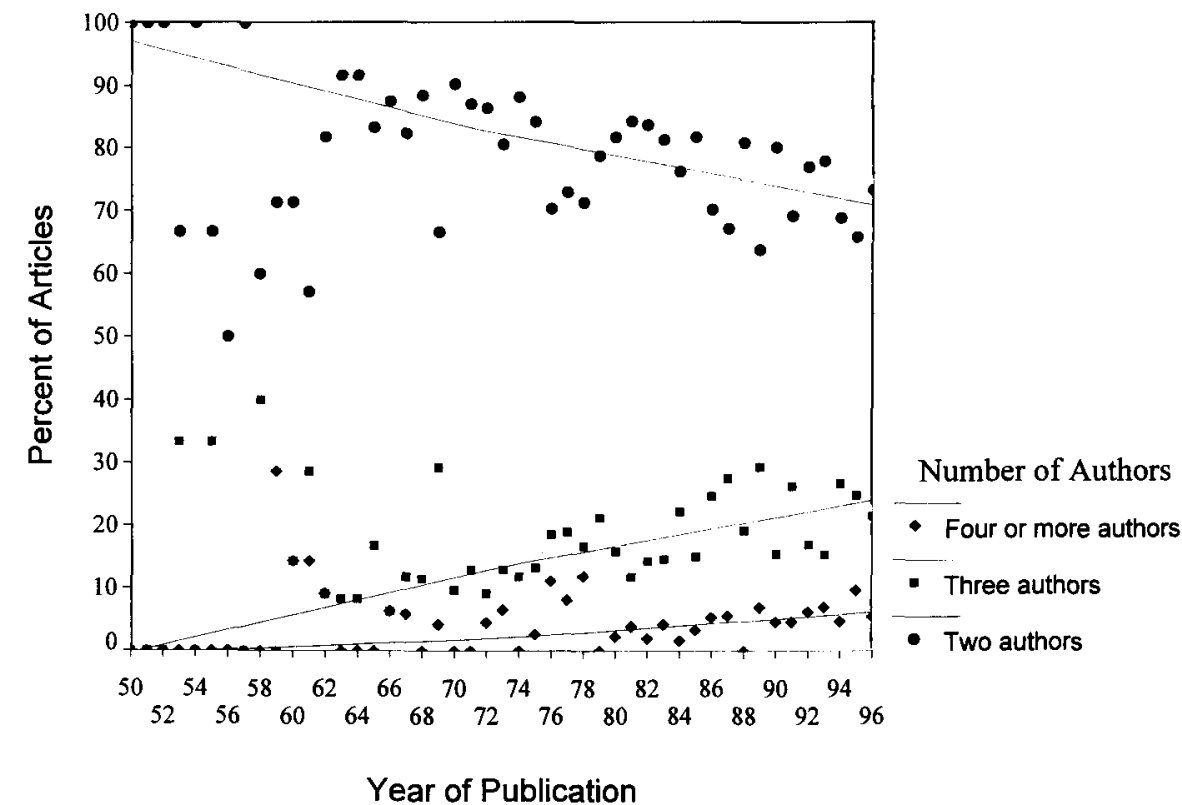

Note: $\alpha=.99$. 
Figure 3A

Percent of Articles by Sex of the Author(s) and Year of Publication: At Least One Male Author

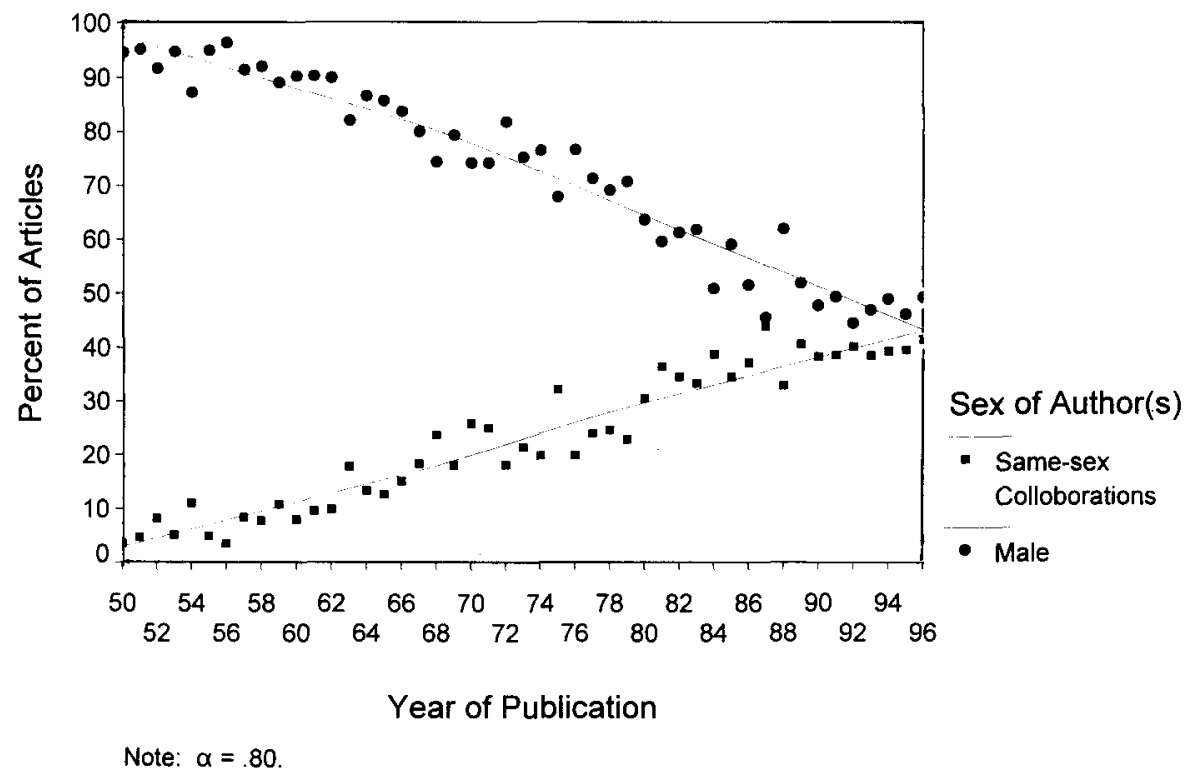

against its respective independent variable, and then adding a loess smoothing to the graph of the respective residuals to examine if there was dependence of the residuals on the respective independent variable. ${ }^{7}$ Our objectives were twofold: (1) to produce a loess curve on the data graph that was as smooth as possible but captured all of the relevant structure existing within the data; and (2) to produce a loess curve on the residual graph that was nearly a horizontal line, since the residuals should be variation in the dependent variable not explainable by the respective independent variable (see Cleveland, 1994, 173-75; Jacoby 1997, 74-77). In a footnote for each figure, we report the $\alpha$ value used in the data analysis between the respective variable and publication date. We employed an $\alpha$ value of .80 in all the residual analyses. ${ }^{8}$

Second, to fully appreciate the magnitude of the change over time, we calculated the percent of articles by authorship coding and the percentage point changes in our data. We discuss percentages and their changes by decade and by journal."

\section{Results}

\section{Findings Over Time: Collaborative Trends and Patterns}

Overall, close to $30 \%$ of all the articles published in the three journals from 1950 to 1996 were multiple authored. Figure 1 presents the percent of multiple-authored articles across all the years. Although there is year-to-year variation, there has been a steadily increasing trend toward more multipleauthored articles over the last four decades.

As Table 1 shows, the percentage of multiple-authored articles, in aggregate, has increased seven-fold since the 1950s and almost one-half of the articles are now multipleauthored.

A more detailed examination of the trend in each journal reveals that, with the exception of APSR, multiple-authored articles have become predominant (see Table 1).

As can be seen in Figure 2 (see, also, Table 1), our analysis revealed other noteworthy trends and patterns in political science journals. First, as a percentage of the multiple-authored articles over time, articles produced by two authors have steadily decreased by close to 12 percentage points. Second, articles produced by three authors have nearly doubled, from $10.9 \%$ in the 1950 s to $20.9 \%$ in the 1990 s. Third, those articles with four or more authors have increased slightly over time, from $4.3 \%$ in the 1950 s to $6.1 \%$ during the 1990s (note, however, that there was a very slight decrease in the 1980s).

Although each journal showed a similar trend toward increased multiple authorship of articles, some
Figure 3B

Percent of Articles by Sex of the Author(s) and Year of Publication: At Least One Male Author

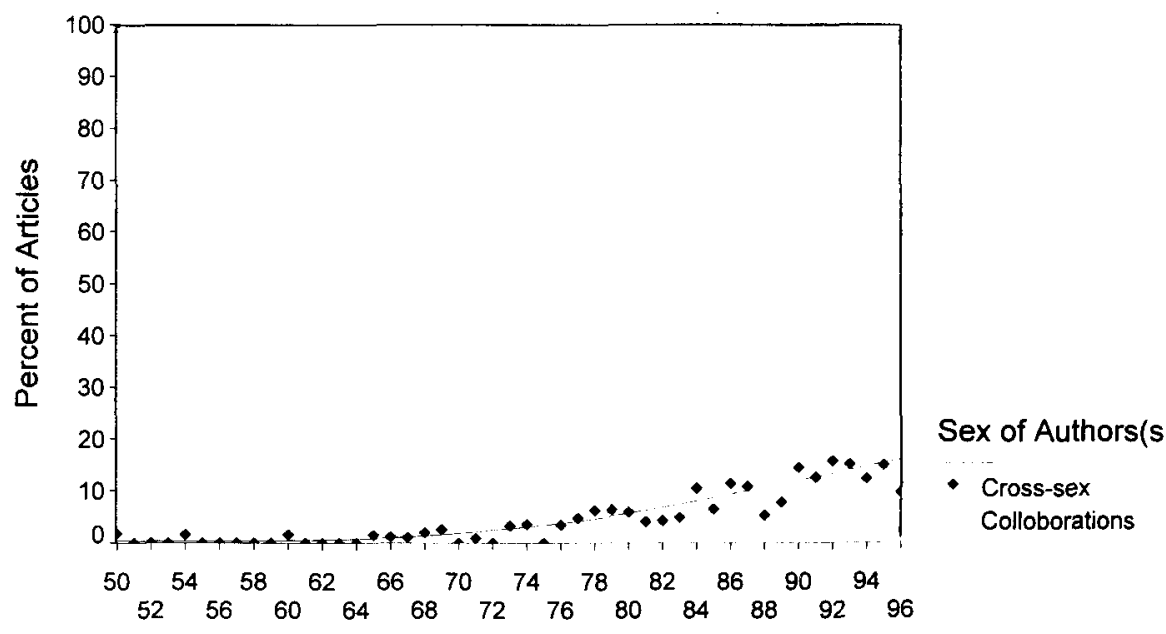

Year of Publication 


\begin{tabular}{|c|c|c|c|c|c|}
\hline \multirow[b]{2}{*}{ Journal } & \multirow[b]{2}{*}{$\begin{array}{c}\text { Percent } \\
\text { Multiple } \\
\text { Authorship }\end{array}$} & \multicolumn{3}{|c|}{ Multiple-Authored Article } & \multirow[b]{2}{*}{$(\mathrm{N})$} \\
\hline & & $\begin{array}{l}\text { Percent } \\
\text { Two } \\
\text { Authors }\end{array}$ & $\begin{array}{l}\text { Percent } \\
\text { Three } \\
\text { Authors }\end{array}$ & $\begin{array}{c}\text { Percent } \\
\text { Four or } \\
\text { More } \\
\text { Authors }\end{array}$ & \\
\hline \multicolumn{6}{|l|}{$\begin{array}{l}\text { Political Science } \\
\text { Journals* }\end{array}$} \\
\hline 1950-1959 & 6.8 & 84.8 & 10.9 & 4.3 & 677 \\
\hline $1960-1969$ & 15.7 & 81.3 & 14.6 & 4.2 & 915 \\
\hline $1970-1979$ & 25.5 & 80.7 & 14.7 & 4.6 & 1,279 \\
\hline $1980-1989$ & 41.3 & 76.4 & 20.0 & 3.5 & 1,344 \\
\hline $1990-1996$ & 49.2 & 73.0 & 20.9 & 6.1 & 935 \\
\hline \multicolumn{6}{|l|}{ PSR } \\
\hline 1950-1959 & 8.5 & 81.8 & 15.2 & 3.0 & 387 \\
\hline $1960-1969$ & 18.7 & 78.4 & 14.9 & 6.8 & 396 \\
\hline 1970-1979 & 26.3 & 80.8 & 14.4 & 4.8 & 475 \\
\hline $1980-1989$ & 43.6 & 73.7 & 21.2 & 5.1 & 451 \\
\hline $1990-1996$ & 45.3 & 72.9 & 20.4 & 6.9 & 318 \\
\hline \multicolumn{6}{|l|}{ AJPS } \\
\hline $1950-1959$ & 3.8 & 50.0 & 0.0 & 50.0 & 53 \\
\hline $1960-1969$ & 15.4 & 85.3 & 14.7 & 0.0 & 221 \\
\hline $1970-1979$ & 28.1 & 80.6 & 13.9 & 5.6 & 384 \\
\hline $1980-1989$ & 44.4 & 75.4 & 20.8 & 3.8 & 412 \\
\hline $1990-1996$ & 51.1 & 66.7 & 25.0 & 8.3 & 282 \\
\hline \multicolumn{6}{|l|}{ JOP } \\
\hline 1950-1959 & 4.6 & 100 & 0.0 & 0.0 & 237 \\
\hline $1960-1969$ & 12.1 & 83.3 & 13.9 & 2.8 & 298 \\
\hline $1970-1979$ & 22.1 & 80.6 & 16.1 & 3.2 & 420 \\
\hline $1980-1989$ & 36.2 & 80.5 & 17.8 & 1.7 & 481 \\
\hline 1990-1996 & 51.3 & 78.4 & 18.0 & 3.5 & 335 \\
\hline
\end{tabular}

* Data are aggregated from APSR, AJPS, and JOP.
In Figure 3, we present trends of authorship by sex over time. Here, we sought to examine gender homogeneity in authorship to determine whether females differed from males with respect to their involvement in single-authored articles, same-sex collaborations, and cross-sex collaborations. Figures $3 \mathrm{~A}$ and $3 \mathrm{~B}$ display the percentages of all articles for which a male was an author or coauthor; Figures $3 \mathrm{C}$ and $3 \mathrm{D}$ show these percentages for female authors.

As can be seen in Figure 3A, there was a downward trend for articles authored singly by males and a steep upward trend in articles authored by just male collaborators. In Figure $3 \mathrm{~B}$, a steady upward trend in cross-sex collaborations is apparent. For example, in the $1950 \mathrm{~s}, 92.7 \%$ of political science articles were authored by one man; in the 1990 s, only $47.3 \%$ of the articles were authored by a man working alone. This is a 45.4 percentage point decrease. Articles authored by all-male collaborators increased 32.3 percentage points between the $1950 \mathrm{~s}$ and the 1990 s (from $6.9 \%$ to $39.2 \%$ ), while articles resulting from cross-sex collaborations increased 13.2 percentage points (from $0.3 \%$ to $13.5 \%$ ).

As evident in Figures 3C and 3D, articles with at least one female author showed trends and patterns similar and dissimilar to maleauthored articles. Articles authored by females working alone strikingly declined over time by 48.1 percentage points (from $88.9 \%$ to $40.8 \%$ ). Same-sex authored (i.e., all females) articles increased over time as did all-male collaborative articles. Articles resulting from cross-sex collaborations steadily increased among female-authored articles from $11.1 \%$ in the 1950 s to $51.2 \%$ in the 1990 s.

During the 1980s and 1990s, cross-sex collaborations were the most common type of authorship for females. Over $51 \%$ of the articles with at least one female author resulted from cross-sex collaborations. Over the same period, $13.5 \%$ of the 
Figure $3 \mathrm{C}$

Percent of Articles by Sex of the Author(s) and Year of Publication: At Least One Female Author

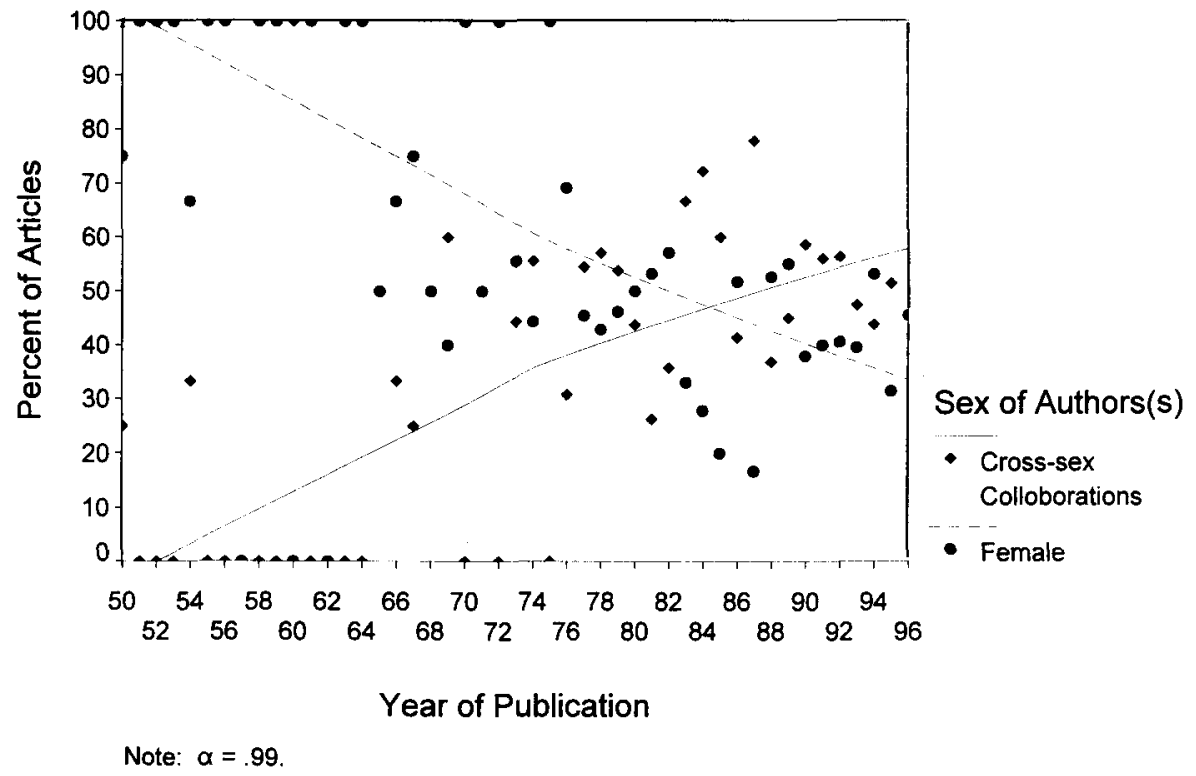

articles with at least one male author represented cross-sex collaborations. Over the past twenty years, females have been 3.8 times more likely to publish articles coauthored with males than were men to publish articles coauthored with women.

The trends and patterns of collaborative authorship varied across the three journals. However, during the 1990s, some noteworthy patterns emerged (not shown in figure). First, solo male-authored and solo female-authored articles decreased in all the journals. Second, JOP has the highest percentage of cross-sex collaborations for both male-authored articles and female-authored articles (15.3\% and $53.6 \%$, respectively), although AJPS is not far behind (14.0\% and $54.0 \%$, respectively). Third, in each journal, cross-sex collaborations are currently the predominant form of authorship for femalesover $50 \%$ in $A J P S$ and $J O P$, and $45.5 \%$ in $A P S R$. The second most common form of authorship among females is single authorship. For males, the two most common forms of authorship are currently single authorship and same-sex collaborative authorship.

\section{Content Characteristics: Trends and Patterns}

In Figure 4, we show the relationship between multiple authorship and the content of an article. We examined two issues: 1) How does the percentage of multiple-authored articles vary with article content? and 2) Can the overall growth of multiple-authored articles be explained by the increase of a particu-

\section{Figure 3D} Least One Female Author lar type of article? We address the latter question by examining whether the percentage point change in multiple-authored articles of a particular type of article differed substantially from the overall percentage point growth in multipleauthored articles. Figure 4A presents the results for articles coded by content as being theoretical or empirical. Figures $4 \mathrm{~B}$ and $4 \mathrm{C}$ present the results for empirical articles coded by the level of statistics used by the authors. ${ }^{12}$

Figure 4A shows that, for any given year, empirical articles were more likely to be multiple authored than theoretical articles. We can also see that the percentage point change in multiple authorship has risen sharply and steadily over time for empirical articles. Specifically, from the 1950 s to the 1990 s, empirical articles that had multiple authors increased by roughly 39 percentage points (from $19.2 \%$ to $58.2 \%$ ). In contrast, multiple authorship of theoretical articles increased by roughly 18 percentage points (from $4.8 \%$ to $22.7 \%$ ) during the same time period. Considered together, these results suggest that the overall growth in multiple authorships was being driven, at least partially, by the growth of empirical articles.

Finally, we examined the trends

Percent of Articles by sex of the Author(s) and Year of Publication: At

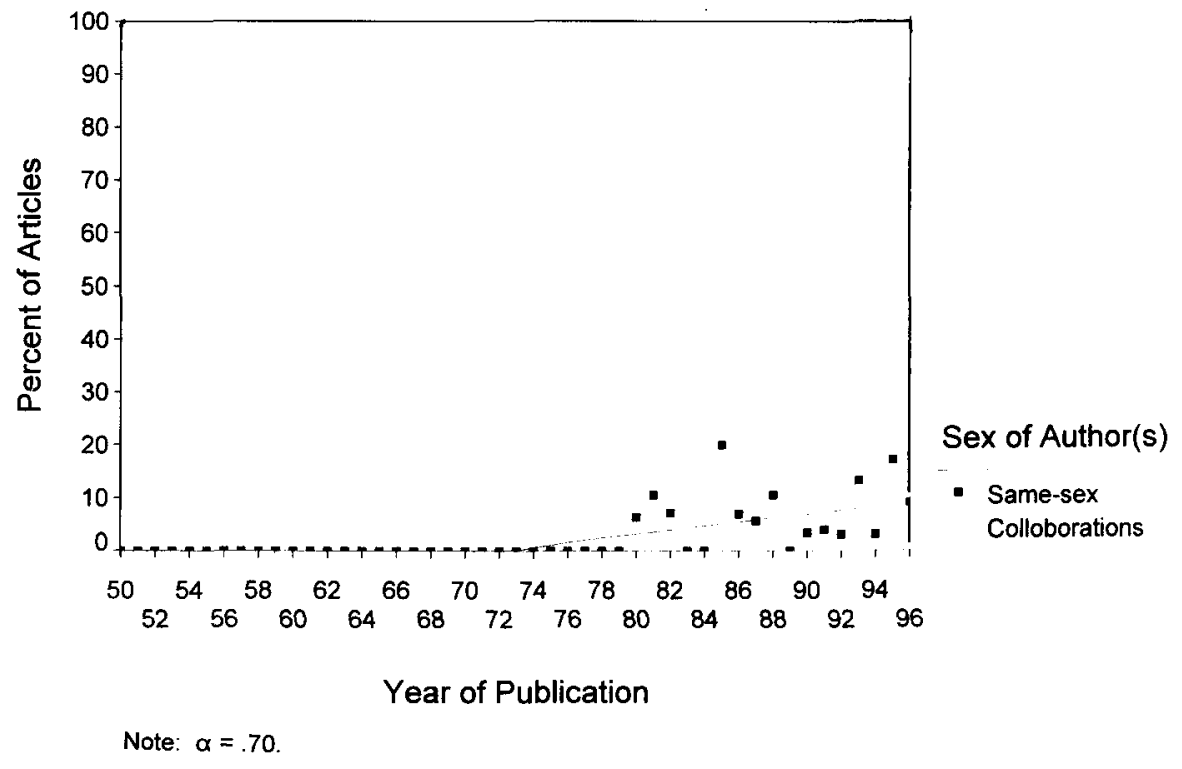


Figure 4A

Percent of Multiple-Authored Articles by Characteristics of Content and Year of Publication: Type of Article

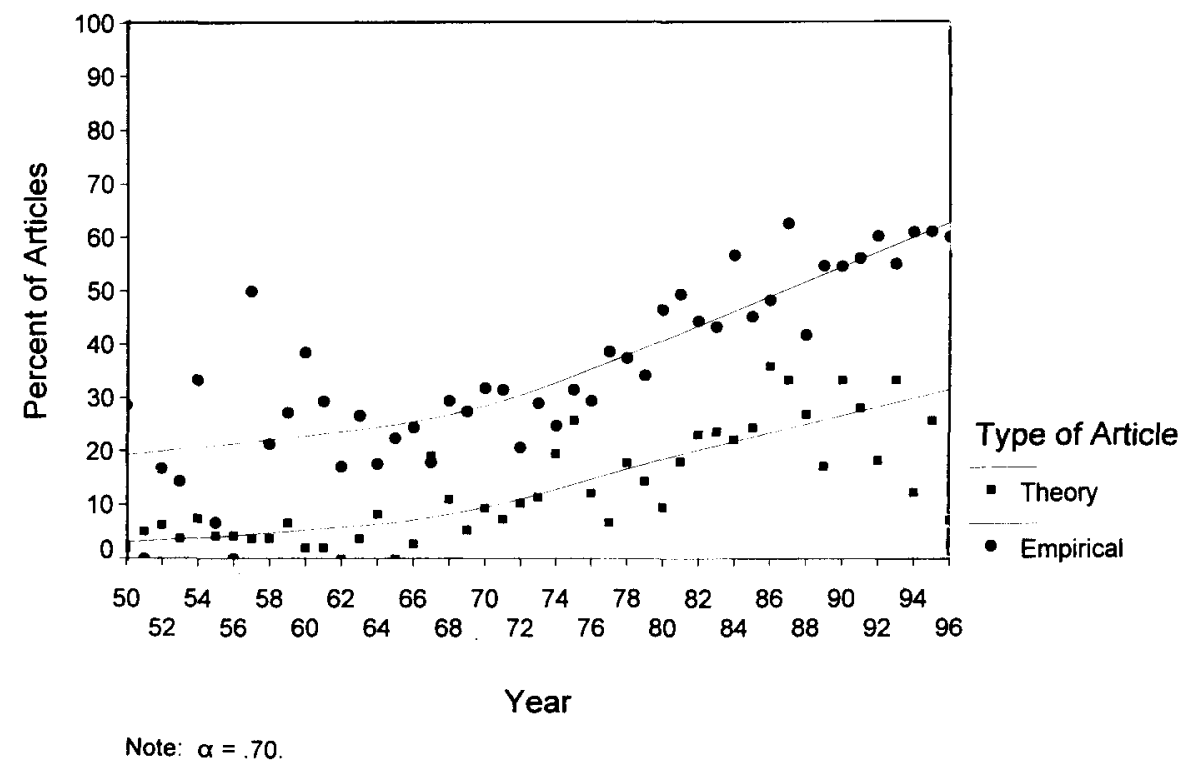

and patterns of multiple authorship of articles employing some type of statistical analysis. As shown in Figures $4 \mathrm{~B}$ and $4 \mathrm{C}$, overall, as the degree of statistical sophistication rose (i.e., as the use of descriptive statistics gave way to bivariate statistics and then to multivariate statistics), the percentage of multiple-authored articles also rose. For example, during the 1950 s, descriptive statistics were used in nearly $19 \%$ of the multiple-authored articles. During the $1990 \mathrm{~s}$, this percentage rose to $50.8 \%$. Similarly, during the same time period, the percentage of multiple-authored articles that included bivariate statistics increased from $40.0 \%$ to $58.5 \%$. Multiple-authored articles whose authors used multivariate statistics also increased from zero to $59.5 \%$ of the articles.

Looking at Figure $4 \mathrm{C}$, it is clear that in the mid-1970s the percentage of multiple-authored articles in which the authors used multivariate statistics surpassed the percentage of multiple-authored articles in which the authors used bivariate statistics. ${ }^{13} \mathrm{~A}$ few plausible contextual explanations as to why this crisscross pattern occurred are in order. First, as we discussed earlier, the rise of the behavioralist movement coincided with the increased availability of computers (mostly mainframes) and statistical software packages, leading social scientists to develop and employ more complicated and labor-intensive statistical techniques. Second, during the 1970s, large-scale data sets became available for use on mainframes, where multivariate statistical analyses could be more easily performed than before.

For each journal, the use of statistics in multiple-authored articles increased over time, especially the use

\section{Figure 4B}

of multivariate statistics (not shown in figure). For example, during the 1950 s, none of the multiple-authored articles published in APSR included multivariate statistics. In the 1990 s, $65.9 \%$ of multiple-authored articles included multivariate statistics. In sum, the use of statistics-descriptive, bivariate, or multivariate-in multiple-authored articles has increased over time, overall and within each journal. We should also note that these results held when type of article and statistical methods were controlled for in a multivariate logit analysis. ${ }^{14}$

\section{Discussion}

The nature of authorship in social science has decidedly changed over the past thirty years. The majority of social science articles are now authored by two or more scholars, and political science mirrors this trend. Approximately half of all the articles published in political science are multiple authored - a jump of 42 percentage points since the fifties. The percentage point increase of multiple authorship in political science far exceeds the percentage point increase in either sociology or economics. Furthermore, the level of collaborative writing is highest in $A J P S$ and $J O P$, which each have just Percent of Multiple-Authored Articles by Characteristics of Content
and Year of Publication: Type of Statistical Analysis

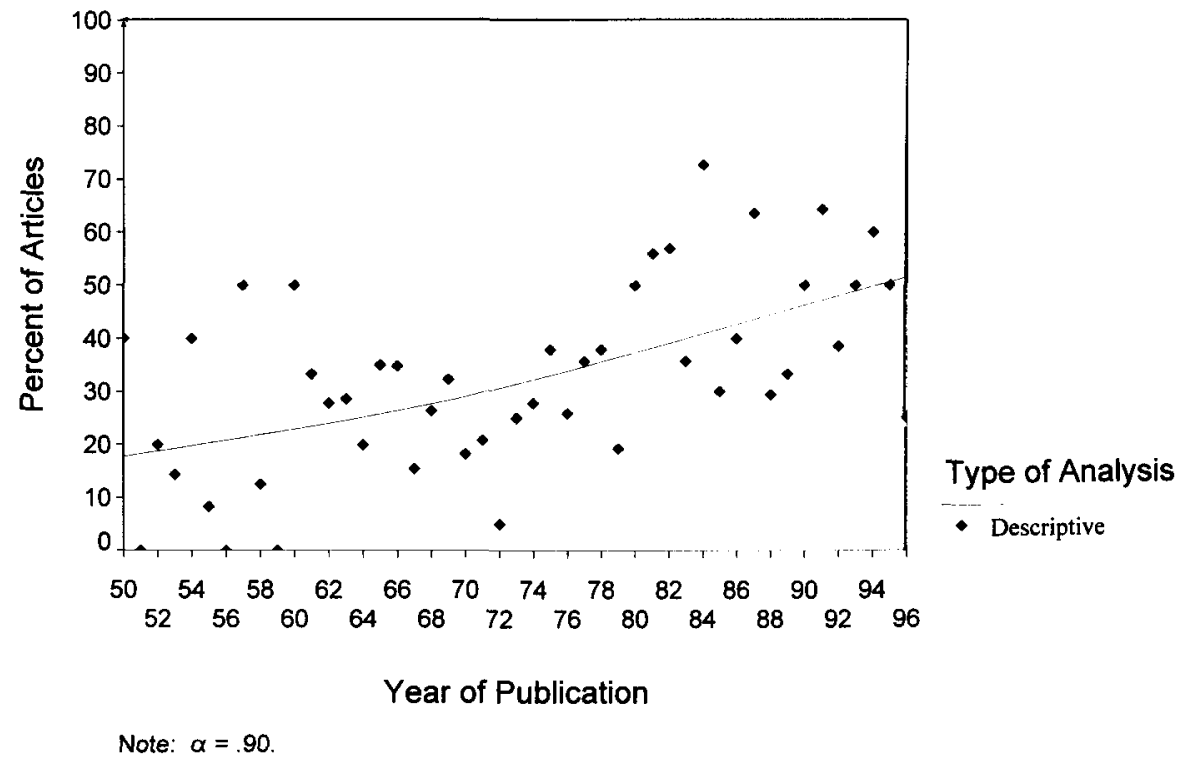


Figure 4C

Percent of Multiple-Authored Articles by Characteristics of Content and Year of Publication: Type of Statistical Analysis

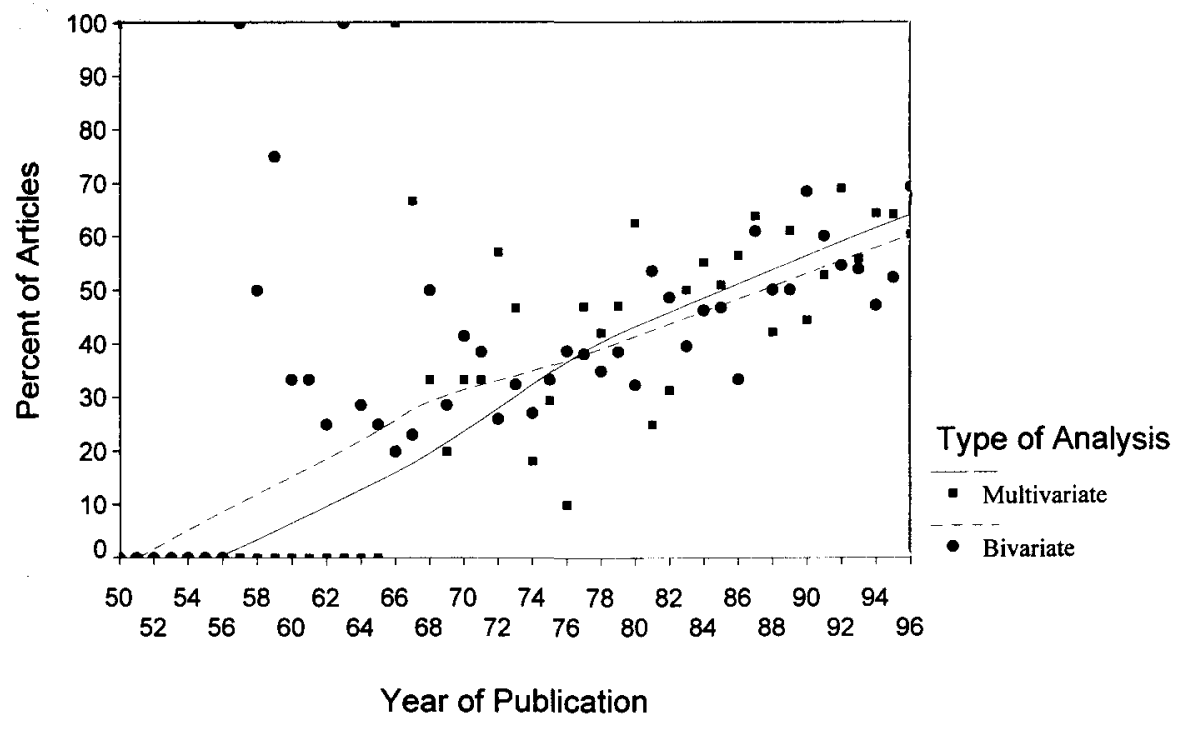

Note: $\alpha=.75$

over half of their articles written by scholars working in collaboration.

Taken together, these findings suggest that multiple authorship is becoming the norm within political science. The traditional picture of the scholar laboring independently on his or her research no longer seems valid. As noted previously, the reality of pervasive collaborative research raises salient policy issues within academia. Most notably, in merit, tenure, and promotion decisions, it may be misleading, if not unfair, to evaluate faculty by traditional criteria that presumed an article would be individually authored. The risk of devaluing collaborative works may be especially pronounced when upper-level university or college officials come from an earlier generation and/or from a discipline (e.g., history) in which coauthorship was, or is, uncommon.

At the same time, as multiple authorship becomes increasingly prevalent, evaluating faculty may well pose special challenges. Disentangling the relative contribution of authors may not be as simple as seeing how many first-authored publications a scholar has produced. The ordering of authors' names on a publication is not always a reflection of who contributed what to the article. The ordering of names can be

determined by disciplinary norms (e.g., economics journals tend to list authors' names alphabetically), the status of authors, some random procedure such as a coin flip, and personal relations (Hudson 1996; Fine and Kurdek 1993; Zuckerman 1968). Evaluations may be further complicated by the realization that

Our findings suggest that in the "traditional" political science journals, women mostly collaborate with men, whereas in Women and Politics women primarily publish single-authored articles. opportunities to coauthor research and, thus, to be "productive" may be structured by factors ranging from the type of scholarship a person conducts to race, age, and gender (McDowell and Smith 1992).

In this regard, it is noteworthy that among women in the social sciences, but particularly among women in political science, the dominant form of authorship has become cross-sex collaborations. Just over half of the articles published by women in the leading journals resulted from cross-sex collaborations. In contrast, men appear more likely to author articles on their own or to coauthor articles with other men.

The pervasiveness of female scholars collaborating with males again raises the issue of how multiple-authored articles should be evaluated. If these works are devalued, or if women's contributions are implicitly attributed to male coauthors, then the high level of multiple authorship among females may help to produce social (e.g., professional recognition, promotion) and economic (e.g., salary, merit pay) inequality within academia.

Of course, collaborative work also may be seen as a positive development in political science. There is some evidence in economics that coauthorship increases productivity (Durden and Perri 1995) and the number of citations an article garners (Eisenhauer 1997). Furthermore, the high percentage of articles collaboratively authored by males and females suggests that gender barriers to mentorship and acceptance into research networks in the discipline may well be growing weaker.

We should note one qualification on this finding regarding women's participation in cross-sex collaboration. After looking at our results, we wondered whether the patterns of female authorship would differ in forums devoted to gender issues. Accordingly, we recorded the sex and number of the authors who published in Women and Politics $(W P)$ from its inception in 1980 to $1996 . .^{15}$ This analysis revealed that males published only $15 \%(\mathrm{~N}=37)$ of the articles, either alone or with other males, and that women published the remaining $85 \%$ of the articles, be it alone, with other women, with a male, or with other males. Of articles with at least one female author, $66 \%(\mathrm{~N}=144)$ were single-authored, $17 \%(\mathrm{~N}=37)$ were collaborations that included at least one male, and $17 \%(\mathrm{~N}=36)$ were 
coauthored or multiple authored with women.

Our findings suggest that in the "traditional" political science journals, women mostly collaborate with men (see Figure 3C), whereas in $W P$ women primarily publish singleauthored articles. Our analysis does not allow us to determine whether this authorship pattern reflects women's tendency to direct their genderrelated research to $W P$ in the anticipation of a favorable response and/or the tendency of the more traditional political science journals not to publish gender-related research when such work competes with submissions that address broader or more "mainstream" topics. We leave this line of inquiry for future studies. In any case, $W P$ clearly provides female authors with opportunities to publish single- authored works. These works not only contribute to our growing body of knowledge, but also are likely to enhance the visibility and advance the careers of female scholars, graduate students, and nonacademics.

Several other findings also warrant comment. First, consistent with our expectations, the data suggest that multiple authorship is less common for theory articles and more common for empirical analyses. Second, supportive of past research (De Maio and Kushner 1981) and our hypothesis, the data suggest that multiple-authored articles tended to increase as the statistical methods used in the analysis became more sophisticated. Since political scientists rely increasingly on more advanced quantitative methods, it is plausible to anticipate that the trend toward collaborative work will continue.

In closing, multiple authorship has become the norm for research articles in political science. Future research is warranted to show how collaborative research develops (i.e., employing network analysis), differences and similarities across subfields (e.g., American politics, international affairs, comparative politics), how the Internet influences domestic and international collaborations, and how collaboration affects both the growth of knowledge within the discipline and the development of careers of political scientists within academic institutions. All these areas of research continue in the tradition of reflecting on the evolution and state of political science.

\section{Notes}

* We thank David Moore at the Institute for Data Sciences for his help with STATA

1. "Social science" disciplines include anthropology, area studies, criminology, demographics/population studies, economics, econometrics, geography, human/individual and family development, public policy analysis, sociology, statistics, urban affairs/studies, social sciences (general), and social sciences (other). "Political science" includes international relations/affairs, political science/government, and public administration. This information is available through 1995. We did not compare the current decade to the 1950) because we only have five years of data in the 1990s. Comparing five years of data to 10 years of data would be misleading. We did not compare year to year (e.g., 1950 to 1995) because there could be extreme year-to-year variation that masks the long-term trends.

2. The last issue of the 1996 volume of JOP was not coded because it was not available on February 1, 1997, when we collected our data.

3 . We used the cumulative index for volumes 2-10 of MJPS (AJPS) because these volumes were not available through interlibrary loan from any college or university in Ohio. The cumulative index did not reference volume 1 (1957).

4. We did code the status (e.g., professor, students) of the author(s) when it was given However, we could not use this variable in any subsequent analysis because $A P S R$ did not provide the status of the author(s) until 1986, JOP inconsistently provided the status of the author(s), and AJPS never has reported this information.

5. The data collection variable was defined according to the data collection process used by the author(s) and was coded as primary $(\mathrm{N}=69)$, secondary $(\mathrm{N}=2,726)$, a combination of primary and secondary $(\mathrm{N}=90)$, computer simulation $(\mathrm{N}=11)$, none (e.g., theory arguments, methodological or statistical discussions $[\mathbf{N}=1,595]$ ), or a mathematical proof $(\mathrm{N}=464)$. We were interested in looking at patterns of multiple authorship by primary types of data collection because we hypothesized that articles that employed primary data collection techniques would be more likely to be the work of multiple authors than other types of articles. After we looked at the frequency distribution of this variable, we realized that only $3.1 \%(\mathrm{~N}=159)$ of the articles used primary or primary and secondary data We decided that we could not reliably plot patterns of multiple authorship over time using primary types of data collection.

6 . We thank the anonymous reviewer who suggested this technique to us; it proved very useful in presenting our results. For those readers who are not familiar with this technique, section 3 of Beck and Jackman (1998) provides an excellent overview of scatterplot smoothing.

7. According to Jacoby, "there should be no discernable pattern within the residuals" $(1997,74)$. In a loess fit, $\alpha$, is the proportion of observations that are used in each local regression (i.e., the bandwidth or span). Alpha is specified as a number between 0 and 1 .

8. We used STATA, version 5.0 (1997) for data and residual analyses (i.e., to determine the $\alpha$ values), and SPSSPC, version 6.1.3 (1993) to produce the figures. Note that SPSSPC will not allow the user to vary $\alpha$ for different variables within one overlay figure. Because of this, we present multiple figures for the different categories of the respective variable.

9. The data are available upon request from Bonnie Fisher at Bonnie.Fisher $@$ uc.edu.
10. The three journals included in Fisher et al. (1998) analysis were American Sociological Review, American Journal of Sociology, and Social Forces.

11. Hudson included eight journals in his 1996 analysis: American Economic Review, Economic Journal, Econometrics, Review of Economics and Statistics, Review of Economic Statistics, Review of Economics Studies, Journal of Political Economy, Quarterly Journal of Economics, and Economica.

12. Only those articles in which statistics were used were included in the analyses reported in Figures $4 \mathrm{~B}$ and $4 \mathrm{C}(\mathrm{N}=1,248)$.

13. Statistically this happened because during the 1950 s there were only 18 multipleauthored articles that used any type of statistics and during the 1960s the number increased to 100 (5 of which used multivariate statistics). For any given year during these two decades, the number of articles that used any type of statistical analysis is quite small, hence our graphed percentages are case sensitive (e.g., one multiple-authored article that included statistics may represent $100 \%$ of the articles for that year). As is evident in Figure $4 \mathrm{C}$, there is large variation in the year-to-year percentages during these two decades, especially in articles using bivariate analysis. Note that during these two decades, the percentage of multiple-authored articles that used multivariate statistics was higher than those using bivariate statistics $(31.3 \%$ compared with $41.7 \%$, and $34.6 \%$ compared to $37.5 \%$, re spectively). Since the purpose of the loess curve is to summarize the middle of the distribution of percentage of articles for each year, the curve prior to 1970 is sensitive to the extreme variation in our data. Thus, our smoothing curve was estimated using the data after 1969 . 
14. We also investigated these trends and patterns using multivariate logit models that predict the probability of an article being multiple authored. These models confirmed the previously discussed bivariate results, but do offer two additional insights. First, while there is a positive trend in multiple authorship for articles in general, the growth is largest for articles with at least one female author. Second, the content of an article is an important predictor of multiple authorship. The logit results suggest that as the sophisti- cation of the statistical analysis increases in quantitative articles so does the likelihood of multiple authorship

15. The methods detailed above to code articles in the other journals was used to code the articles published in $W P$.

\section{References}

Baum, William C., G.N. Griffiths, Robert Matthews, and Daniel Scherruble. 1976. "American Political Science Before the Mirror: What Our Journals Reveal About the Profession." Journal of Politics 38(4): 895-917.

Beck, Nathaniel, and Simon Jackman. 1998. "Beyond Linearity by Default: Generalized Additive Models." American Journal of Political Science 42(2): 596-627.

Burton, Dori-Jean. 1979. "Ten Years of Affirmative Action and the Changing Status of Women in Political Science." PS: Political Science and Politics 12(March): 18-22.

Cleveland, William S. 1979. "Robust Locally Weighted Regression and Smoothing Scatterplots." Journal of the American Statistical Association 74(388): 829-36.

- 1994. The Elements of Graphing Data. Summit, NJ: Hobart Press.

Cnudde, Charles F. 1986. "Care Using the Social Science Citation Index: Comment on Klingemann's Method." PS: Political Science and Politics 19(December): 85052.

De Maio, Gerald, and Harvey W. Kushner. 1981. "Quantification and Multiple Authorships in Political Science." Journal of Politics 43(1): 181-93.

Durden, Garey C., and Timothy J. Perri. 1995. "Coauthorship and Publication Efficiency." Atlantic Economics Joumal 23(1): 69-78.

Eisenhauer, Joseph. 1997. "Correspondence." The Journal of Economic Perspectives 11(1): 191-92.

Endersby, James W. 1996. "Collaborative Research in the Social Sciences: Multiple Authorship and Publication Credit." Social Science Quarterly 77(2): 375-92.

Fine, Mark A., and Lawrence A. Kurdek. 1993. "Reflections on Determining Authorship Credit and Authorship Order on Faculty-Student Collaboration." American Psychologist 48(11): 1141-47.

Fisher, Bonnie S., Thomas M. Vander Ven, Craig T. Cobane, Francis T. Cullen, and Nicolas Williams. 1998. "Trends in Multiple-Authored Articles in Criminology and Criminal Justice: A Comparative Disciplinary Analysis." Journal of Criminal Justice Education 9(1): 19-38.

Garand, James C. 1990. "An Alternative Interpretation of Recent Political Science Journal Evaluations." PS: Political Science and Politics 23(September): 448-51.

Giles, Michael W., Francie Mizell, and David Patterson. 1989. "Political Scientists' Jour- nal Evaluations Revisited." PS: Political Science and Politics 22(September): 613 17.

entists' Evaluation of Sixty-Three Journals." PS: Political Science and Politics 8(September): 254-57.

Gleditsch, Nils Peter. 1993. "The Most-Cited Articles in JPR." Journal of Peace Research 30(4): $445-49$.

-. 1996. "The APSR Hall of Fame: A Comment." PS: Political Science and Politics 29(December): 637-38.

Grant, Linda, and Kathryn B. Ward. 1991. "Gender and Publishing in Sociology." Gender and Society 5(2): 207-23.

Hesli, Vicki, and Barbara Burrell. 1995. "Faculty Rank among Political Scientists and Reports on the Academic Environment: The Differential Impact of Gender on Observed Patterns." PS: Political Science and Politics 28(March): 101-11.

Hudson, James. 1996. "Trends in Multi-Authored Papers in Economics." Journal of Economic Perspectives 10(3): 153-58.

Jackman, Robert W., and Randolph M. Siverson. 1996. "Rating the Rating: An Analysis of the National Research Council's Appraisal of Political Science Ph.D. Programs." PS: Political Science and Politics 29(June): 155-60.

Jacoby, William G. 1997. Statistical Graphics for Univariate and Bivariate Data. Thousand Oaks, CA: Sage Publications.

Katz, Richard S., and Munroe Eagles. 1996. "Ranking Political Science Programs: A View from the Lower Half." PS: Political Science and Politics 29(June): 149-54.

Kelly, Rita Mae, Linda M. Williams, and Kimberly Fisher. 1993. "An Assessment of Articles About Women in the 'Top 15' Political Science Journals." PS: Political Science and Politics 26(September): $544-$ 58.

Klingemann, Hans-Dieter. 1986. "Ranking the Graduate Departments in The 1980s: Towards Objective Qualitative Indicators." PS: Political Science and Politics 19(September): 651-61.

—, Bernard Groffman, and Janet Campagna. 1989. "The Political Science 400: Citations by Ph.D. Cohort and by Ph.D.-Granting Institution." PS: Political Science and Politics 22(June): 258-70.

Lester, James P. 1990. "Evaluating the Evaluators: Accrediting Knowledge and the Ranking of Political Science Journals."
PS: Political Science and Politics 23(September): $445-46$.

Lowery, Robert C., and Brian D. Silver. 1996. "A Rising Tide Lifts All Boats: Political Science Departments Reputation and the Reputation of the University." PS: Political Science and Politics 29(March): 16167.

McDowell, John M., and Janet Kiholm Smith. 1992. "The Effect of Gender-Sorting on Propensity to Coauthor: Implications for Academic Promotion." Economic Inquiry 30(1): $68-82$.

Miller, Arthur H., Charles Tien, and Andrew A. Peebler. 1996a. "The American Political Science Review Hall of Fame: Assessments and Implications for an Evolving Discipline." PS: Political Science and Politics 29(March): 73-83.

—. 1996b. "Department Ranking: An Alternative Approach." PS: Political Science and Politics 29(December): 704-17.

Morgan, David R., and Michael R. Fitzgerald. 1977. "Recognition and Productivity Among American Political Science Departments." Western Political Quarterly 30(3): 342-50.

National Research Council. 1995. Survey of Eamed Doctorates. Washington, DC: National Academy Press.

Price, Derek J. de Solla, and Donald deB. Beaver. 1966. "Collaboration in an Invisible College." The American Psychologist 21(11): 1011-18.

Sarkees, Meredith Reid, and Nancy E. McGlen. 1992. "Confronting Barriers: The Status of Women in Political Science." Women and Politics 12(4): 43-83.

SPSS, Inc. 1993. SPSS for Windows: Base System User's Guide, Release 6.0. Chicago: SPSS Inc

STATACorp. 1997. Stata Statistical Software: Release 5.0. College Station, TX: Stata Corporation.

Susser, Bernard. 1992. Approaches to the Study of Politics. New York: MacMillan.

Wildavsky, Aaron. 1986. "On Collaboration." PS: Political Science and Politics 19(June): 237-48.

Young, Cheryl D. 1995. "An Assessment of Articles Published by Women in 15 Top Political Science Journals." PS: Political Science and Politics 28(September): 52533.

Zuckerman, Harriet A. 1968. "Patterns of Name Ordering Among Authors of Scientific Papers: A Study of Social Symbolism and Its Ambiguity." The American Journal of Sociology 74(3): 276-291. 